\title{
EVALUASI TINGKAT KEBERHASILAN PELAKSANAAN PROGRAM INSEMINASI BUATAN PADA SAPI BALI \\ DI KABUPATEN JAYAPURA
}

\author{
Johan F. Koibur \\ INTISARI
}

Penelitian ini bertujuan untuk mendapatkan informasi mengenai tingkat keberhasilan Inseminasi Buatan (IB) pada ternak sapi Bali di Kabupaten Jayapura. Obyek pada penelitian ini adalah 48 ekor sapi di Kecamatan Nimbokrang dan 50 ekor sapi di Kecamatan Skanto. Jumlah sapi tepilih merupakan dari $10 \%$ populasi ternak sapi peserta IB, pada 30 peternakan peserta program IB untuk setiap kecamatan. Penelitian ini merupakan studi kasus ternak sapi Bali peserta program IB. Data yang dihimpun dianalisis secara deskriptif tabulasi. Hasil penelitian menunjukkan berturutturut nilai Service per Conception (S/C), Conception Rate (CR), dan angka kelahiran ternak sapi Bali di Kabupaten Jayapura sebesar 1,74; 76,73\%; dan 73,5\%. Hasil ini dapat dikatakan baik karena telah memenuhi standar nasional. Terdapat hubungan yang signifikan antara S/C, C.R, dan Calving rate.

(Kata kunci : Inseminasi buatan, Sapi Bali, S/C, Conception rate, Calving rate).

Buletin Peternakan $29(3): 150$ - 155, 2005

'Fakultas Peternakan Perikanan dan Ilmu Kelautan UNIPA Manokwari. 


\title{
EVALUATION ON THE SUCCES LEVEL OF ARTIFICIAL INSEMINATION PROGRAM WITH BALI CATTLE IN JAYAPURA REGENCY
}

\begin{abstract}
This research was aimed to collect information on the success level of artificial insemination (IB) wiht Bali cattle in Jayapura Regency. The object of the study were 48 cattle in Nimbokrang District and 50 cattle in Skanto District from $10 \%$ of cattle population of AI participants, property of 30 cattle husbandries which were AI program participant at each District. The study was based on case study, where the data were collected and analyzed by descriptive tabulation. The result indicated that Service per Conception (S/C), Conception rate (CR) and Calving rate of Bali cattle of Jayapura Regency was $1.74 ; 76.73 \% ; 73.75 \%$, respectively. It was suggested that the result was good, because it reached the national standard. There were significant correlations among $\mathrm{S} / \mathrm{C}, \mathrm{CR}$ and Cal ving rate.
\end{abstract}

(Keywords : Artificial insemination, Bali cattle, Jayapura regency, S/C, Conception rate, Calving rate).

\section{Pendahuluan}

Sapi Bali, merupakan ternak asli Indonesia, memiliki karakteristik yang khas dan nilai ekonomis yang tinggi. Sapi Bali mulanya berkembang dan menyebar hanya di pulau Bali, tetapi kini telah menyebar ke seluruh pelosok Nusantara.

Sapi Bali banyak digunakan dalam program penyebaran sapi ke daerah-daerah transmigrasi karena kemampuannya dalam mengolah tanah pertanian dan daya tahannya terhadap panas (Aziz, 1994), dapat tumbuh dan berkembang pada kondisi lingkungan yang kurang baik serta tahan caplak (Udayana, 2001), mampu memanfaatkan hijauan yang bermutu rendah dan memiliki tingkat fertilitas yang tinggi $83-86 \%$ (Darmadja, 1980). Kelebihan-kelebihan ini menjadikan sapi Bali sebagai sapi primadona Indonesia (Bandini, 1997 dan Gunawan, dkk., 1998).

Inseminasi buatan (IB) adalah salah satu teknologi reproduksi yang telah dan sedang diprogramkan oleh pemerintah dalam rangka pembangunan peternakan sebagai upaya peningkatan produktivitas ternak demi meningkatkan pendapatan dan kesejahteraan petani peternak. Melalui teknologi ini peternak dapat memiliki ternak yang berkualitas tanpa harus memiliki pejantan unggul (Salisbury dan Van Demark, 1985).
Pada kawin alam, seekor pejantan hanya dapat melayani 50-70 ekor sapi betina dalam setahun, sedangkan dengan IB seekor pejantan mampu melayani 5000-10.000 ekor betina dalam setahun. IB juga menjanjikan tingkat kebuntingan yang tinggi pada sapi betina yang telah dewasa tubuh ( \pm 18 bulan), sehat, organ reproduksinya normal, dan tidak memiliki cacat genetik (Toelihere, 1985).

Pelaksanaan. IB di Papua pertama kali dilakukan di Kabupaten Merauke pada tahun 1988, selanjutnya di Kabupaten Jayapura dan Sorong pada tahun 1991 (Anonimous, 2000). IB diharapkan mampu memperbaiki kualitas ternak sapi di propinsi ini, sehingga memungkinkan terjadinya keseimbangan tingkat pemotongan yang pada akhimya dapat mempertahankan jumlah populasi.

Dalam upaya peningkatkan mutu genetik dan populasi ternak sapi Bali demi mengantisipasi tingginya permintaan konsumen akan daging sapi, sejak tahun 1991 telah dilaksanakan program IB di Kecamatan Abepura, Kecamatan Nimbokrang, dan Kecamatan Skanto melalui Dinas Peternakan Kabupaten Jayapura dengan menggunakan semen beku yang berasal dari Balai Inseminasi Buatan Singosari (Anonimous, 2000).

Walaupun telah dilaksanakan selama kurang lebih 12 tahun, informasi tentang keberhasilan pelaksanaan program IB di 
Kabupaten Jayapura ini masih sangat minim. Saputra (1999) dalam observasinya di Kecamatan Skanto, menemukan bahwa persentase kebuntingan ternak sapi hasil IB adalah $66 \%$. Tingkat kebuntingan yang dicapai ini cukup tinggi dan dikategorikan berhasil, akan tetapi hasîl ini belum menggambarkan tingkat keberhasilan IB di Kabupaten Jayapura karena hanya diwakili oleh sekelompok peternak dalam satu kecamatan saja, Gambaran keberhasilan IB di Kabupaten Jayapura akan lebih akurat apabila kelompok-kelompok peternak dari beberapa kecamatan yang mengikuti program ini dilibatkan. Dengan demikian penelitian ini dirasa perlu untuk dilakukan

Tujuan dari penelitian ini adalah menghimpun dan menganalisis data program IB di Kecamatan Nimbokrang dan Kecamatan Skanto, Kabupaten Jayapura, untuk mendapatkan informasi mengenai tingkat keberhasilan IB yang telah dilakukan.

Hasil penelitian ini diharapkan bisa membantu para pengambil kebijakan program IB dalam menjalankan program IB ke depan.

\section{Materi dan Metode}

Penelitian ini dilaksanakan selama dua minggu, yaitu tanggal 9-23 Desember 2002 bertempat di Kecamatan Nimbokrang dan Skanto, Kabupaten Jayapura. Bahan yang digunakan dalam penelitian ini adalah kartu IB ternak sapi Bali yang telah dïnseminasi pada lima periode dari tahun 1997/1998 hingga tahun 2001/2002. Alat pada penelitian ini adalah kuisioner dan alat tulis menulis. Metode penelitian yang dipakai adalah metode deskriptif dengan teknik studi kasus, ternak sapi Bali yang mengikuti program IB di Kabupaten Jayapura periode tahun 1997/1998-2001/2002.

Penetapan lokasi dilakukan secara sengaja di dua lokasi yaitu Kecamatan Nimbokrang dan Kecamatan Skanto, yang didasarkan pada intensitas pelaksanaan IB, berdasarkan informasi Dinas Peternakan Kabupaten Jayapura. Pelaksanaan penelitian ini difakukan melalui beberapa tahapan, yaitu survei awal dan pengolahan data.

Survei awal dilakukan untuk mengetahui jumlah kepala keluarga peternak sapi Bali anggota program IB, dan sebaran populasi sapi Bali di Kecamatan Nimbokrang dan Skanto. Penentuan akseptor dan peternakan peserta program IB ditentukan secara acak (simple random sampling) sebanyak $10 \%$ dari 298 peternakan di Kecamatan Nimbokrang dan 10\% dari 300 peternakan di Kecamatan Skanto yang mengikuti program IB dari tahun 1997/19982001/2002. Sapi yang didata di Kecamatan Nimbokrang berjumlah 48 ekor dan di Kecamatan Skanto berjumlah 50 ekor.

Pengumpulan data. dilakukan menggunakan metode wawancara dengan alat bantu kuisioner. Data sekunder diperoleh dari kartu IB di dinas peternakan dan inseminator. Data primer yang dikumpulkan mencakup tanggapan peternak terhadap pelaksanaan IB, pengetahuan peternak terhadap tanda-tanda berahi serta peubah-peubah reproduksi yang mengacu pada efisiensi reproduksi dari pelaksanaan IB. Data lain adalah identitas inseminator dan kinerja di lapangan serta dinas peternakan mengenai perannya memenuhi prasarana dan sarana yang menunjang program IB.

Variabel utama yang diamati dalam penelitian ini meliputi : service per conception (S/C). Data S/C diambil dari inseminator dan Dinas Peternakan yang didasarkan pada kartu pelaksanaan IB. Data yang diperoleh diformulasikan dengan rumus:

$$
\mathrm{S} / \mathrm{C}=\frac{\Sigma \text { straw yg digunakan }}{\Sigma \text { ternak } q \text { bunting }}
$$

Nilai variabel Conception rate (C.R.) diperoleh dari inseminator dan Dinas Peternakan berdasarkan kartu pelaksanaan IB dan diformulasikan sebagai berikut:

$$
C . R .=\frac{\sum \text { ternak } q \text { bunting }}{\sum \text { ternak } q \text { dinseminasi }} \times 100 \%
$$

Data variable Calving rate diambil dengan cara bertanya langsung kepada petemakan dan inseminator yang menangani kegiatan IB di 
lapangan serta Dinas Peternakan yang didasarkan pada kartu pelaksanaan IB, dan diolah dengan rumus:

$$
\Sigma \text { anak lahir sehat }
$$

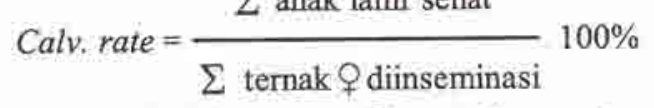

Data-data lain yang dikumpulkan sebagai penunjang dalam penelitian ini adalah asal semen, keadaan prasarana dan sarana serta iklim.

\section{Hasil dan Pembahasan}

\section{Serviceper Conception $(\mathrm{S} / \mathrm{C})$}

Dari penelitian ini diperoleh nilai ratarata S/C dari program IB di Kabupaten Jayapura selama periode 1997-2002 adalah sebesar 1,74 yang diperoleh dari Kecamatan Nimbokrang $(1,49)$ dan Skanto $(2,00)$. S/C ini lebih baik dari yang diperoleh Widodo (2000) di Kenduren $(2,2)$ dan Sembong $(1,93)$; demikian juga dari dan Sembong (1,93); demikian juga dari Toelihere (1985) yang berpendapat bahwa kisaran S/C yang normal untuk Indonesia adalah 1,6-2. Namun masih lebih tinggi bila dibanding dengan target Ditjennak (1997) yaitu sebesar 1,6 (Widodo, 2000). Nilai S/C ternak sapi di Kabupaten Jayapura secara lengkap dapat dilihat pada Gambar 1. Diperolehnya nilai S/C yang baik di Kabupaten Jayapura sangat ditunjang terutama oleh ternak betina $(66 \%)$ yang memenuhi syarat yaitu subur, bebas dari penyakit kemajiran, berstatus reproduksi sudah pernah beranak, dan berkondisi tubuh rata-rata baik (kondisi 3), kesiagapan inseminator melayani pelaporan peternakan tentang tanda berahi temaknya dengan pengalaman berkerja rata-rata 13 tahun, semen beku yang qualified dari Balai Inseminasi Buatan Singosari, dan yang utama peran aktif peternakan, dalam mengikutkan ternaknya pada program IB.

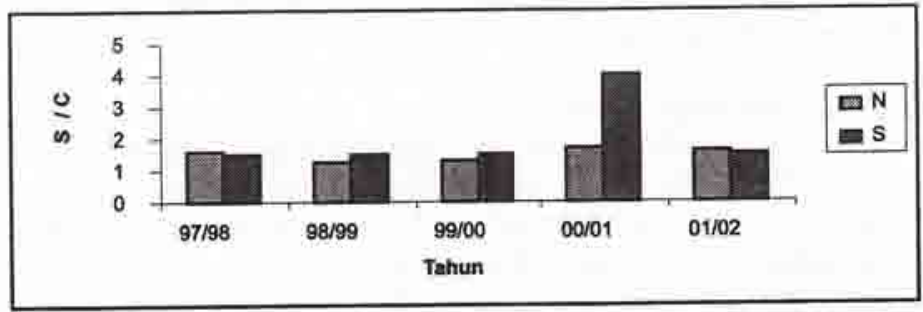

Gambar 1. Nilai S/C ternak sapi Bali selama 5 tahun (1997/1998-2001/2002) di Kabupaten Jayapura (The rate of S/C on Bali cattle for 5 years (1997/1998-2001/2002) in Jayapura Regency).

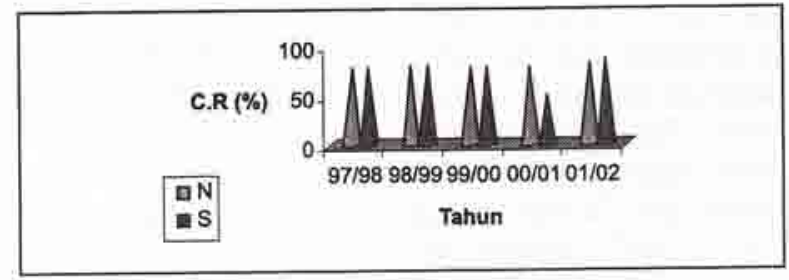

Gambar 2. Angka kebuntingan sapi Bali selama 5 tahun (1997/1998-2001/2002) di kabupaten Jayapura (The conception rate of Bali cattle for 5 years (1997/1998-2001/2002) in Jayapura Regency). 


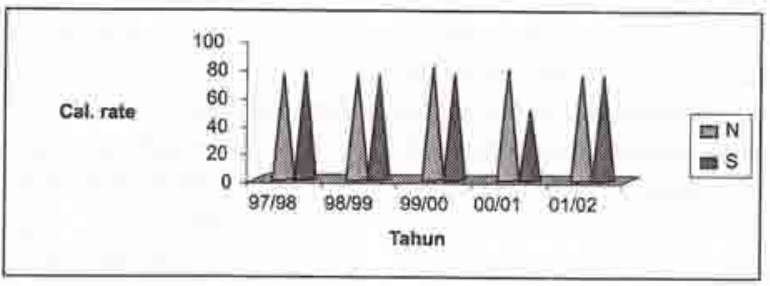

Gambar 3. Angka kelahiran sapi Bali selama 5 tahun (1997/1998-2001/2002) di Kabupaten Jayapura (The calving rate of Bali cattle for 5 years (1997/1998-2001/2002) in Jayapura Regency).

\section{Conception Rate (C.R)}

Angka kebuntingan atau nilai C.R. ternak sapi yang dicapai di Kabupaten Jayapura periode $1997 / 1998-2001 / 2002$ sebesar $76,73 \%$ yang merupakan rata-rata nilai C.R. ternak sapi di Kecamatan Nimbokrang $(79,83 \%)$ dan Skanto $(74,14 \%)$. Conception rate pada ternak sapi di Kabupaten Jayapura jika dibandingkan dengan nilai C.R. yang dicapai di Kunduren $(44,67 \%)$, Kradenan $(61,11 \%)$, dan Sambong $(46,67 \%)$ yang merupakan daerah program IB pada tahun 1977, maka angka kebuntingan yang dicapai di Kabupaten Jayapura sangatlah tinggi.

Nilai C.R. yang diperoleh di Kabupaten Jayapura yag diwakili oleh dua kecamatan ini telah mencapai target yang ditetapkan oleh Ditjennak tahun 1991 sebesar $62,25 \%$ (Widodo, 2000) bahkan menyamai standar negara maju seperti yang disitasi Widodo, 2000 dari Toelihere (1993) bahwa untuk kondisi normal di Indonesia sebenarnya C.R. sebesar $50 \%$ sudah cukup dan angka C.R. 60-70\% merupakan standar dari negara maju. Nilai C.R. ternak sapi program IB di Kabupaten Jayapura diperlihatkan pada Gambar 2.

Dapat dikatakan bahwa baiknya Conception rate di Kabupaten Jayapura dan khususnya Kecamatan Nimbokrang dan Skanto sangat ditunjang terutama oleh ternak betina yang baik kualitas semen yang baik, kemampuan peternak dalam beternak yang baik, inseminator yang cukup berpengalaman, dan faktor penunjang lain yang cukup memadai.

\section{Angka kelahiran (Calving rate)}

Calving rate temak sapi di Kabupaten Jayapura adalah $73,75 \%$ yang merupakan ratarata angka kelahiran ternak sapi di Kecamatan Nimbokrang $(76,78 \%)$ dan Skanto $(70,27 \%)$. Jika dibandingkan dengan beberapa daerah di Indonesia yang sudah mengikuti program IB sejak tahun 1977 rata-rata calving rate di Kabupaten Jayapura ini sudah cukup memuaskan, karena di Kenduren hanya diperoleh $40 \%$ demikian juga dengan di Sembong $47 \%$, tetapi lebih rendah jika

Tabel 1. Hubungan S/C, C.R. dan calving rate ternak sapi peserta program IB di Kabupaten Jayapura tahun 1997/1998-2001/2002 (The corelation between of $S / C, C R$ and calving rate of cattle Bali on IB program participant in Jayapura

Regency for years 1997/1998-2001/2002)

\begin{tabular}{lccc}
\hline $\begin{array}{l}\text { Kecamatan } \\
\text { (District) }\end{array}$ & $\begin{array}{c}\text { Service per } \\
\text { conception }\end{array}$ & $\begin{array}{c}\text { Conception rate } \\
(\%)\end{array}$ & $\begin{array}{c}\text { Calving rate } \\
(\%)\end{array}$ \\
\hline Nimbokrang & 1,49 & 79,33 & 76,78 \\
Skanto & 2 & 74,14 & 70,27 \\
Jayapura & 1,75 & 76,74 & 73,53 \\
\hline
\end{tabular}


dibanding dengan di Kradenan yang sudah mencapai 84\% (Widodo, 2000) dan Kecamatan Oransbari Kabupaten Manokwari $86,90 \%$. Gambaran angka kelahiran ternak program IB di Kabupaten Jayapura tahun 1997/1998. 2001/2002 dapat dilihat pada Gambar 3 .

Dapat disimpulkan bahwa tingginya angka kelahiran ternak sapi di Kabupaten Jayapura secara khusus Kecamatan Nimbokrang dan Skanto disebabkan adanya ternak sapi betina yang subur $(66 \%)$, serta perhatian yang serius dari peternak dan inseminator.

Toelihere (1985) serta Salisbury dan Van Demark (1985), menyatakan bahwa nilai S/C yang rendah akan diikuti C.R. dan Calving rate yang tinggi, pada penelitian ini diperoleh kondisi yang sama seperti ditampilkan pada Tabel 1 .

Dari Tabel 1 dapat dilihat bahwa rendahnya nilai S/C di Kabupaten Jayapura $(1,75)$ yang merupakan rata-rata nilai S/C dari Kecamatan Nimbokrang dan Kecamatan Skanto diikuti oleh tingginya nilai C.R $(76,74)$ dan Calving rate $(73,53)$

\section{Kesimpulan}

Program IB pada ternak sapi Bali tahun 1997/1998-2001/2002 di Kabupaten Jayapura yang diwakili oleh Kecamatan Nimbokrang dan Kecamatan Skanto yang dinilai dari service per conception, conception rate dan calving rate, dapat dikatakan berhasil karena telah memenuhi standar internasional. Program ini akan lebih berhasil jika faktor pakan, inseminator dan faktor-faktor lain yang belum diketahui diteliti dan dicari jalan keluarnya. Pelatihan dan penyuluhan secara intensif kepada peternak akan sangat membantu dalam peningkatan program ini.

\section{Daftar Pustaka}

Anonimous, 2000. Laporan Tahunan Dinas Peternakan Propinsi Papua. Dinas Peternakan Propinsi Papua. Jayapura.

Aziz A. M., 1994. Agroindustri Sapi Potong Prospek Pengembangan Pada PJPT II. Bangkit. Jakarta.

Bandini Y., 1997, Sapi Bali. Penebar Swadaya. Jakarta.

Darmadja D. 1980. Setengah Abad Peternakan Sapi Tradisional Dalam Ekosistem Pertanian di Bali. Disertasi. Universitas Pajajaran. Bandung.

Gunawan, Dicky Pamungkas dan L. Afandy. 1998. Sapi Bali Potensi, Produktivitas dan Nilai Ekonomi, Kanisius. Yogyakarta.

Salisbury G. W. dan N. L. Van Demark, 1985. Fisiologi Reproduksi dan Inseminasi Buatan Pada Sapi. Gadjah Maja Univerity Press. Yogyakarta.

Saputra A. G. S., 1999. Evaluasi Program Inseminasi Buatan Pada Sapi Bali di Kecamatan Skanto Kabupaten Jayapura. Skripsi Sarjana Peternakan Fakultas Pertanian Universitas Cenderawasih. Manokwari. (tidak diterbitkan).

Toelihere M. R., 1985. Inseminasi Buatan Pada Ternak. Angkasa, Bandung.

Udayana A. 2001. Lemak Sapi Sebagai Sumber Energi Substitusi. Poultry Indonesia edisi Januari 2001. Jakarta.

Widodo Puji, 2000. Pengkajian Pelaksanaan Program Inseminasi Buatan Pada Sapi Potong Di Kabupaten Daerah Tingkat II Blora, Jawa Tengah. Skripsi Sarjana Peternakan Institut Pertanian Bogor. 